\title{
Entre lo impactante y lo siniestro. Comentario a la obra de Maurizio Cattelan: Bidibidobidiboo, 1996
}

Between the shocking and the sinister. Commentary on the work of Maurizio Cattelan: Bidibidobidiboo, 1996

\author{
Juan José Castillo Herrera \\ ${ }^{1}$ Historiador del Arte por la Universidad de Málaga (castillo.herrera.juanjo@gmail.com)
}

RESUMEN: A veces lo familiar puede convertirse en siniestro. Aquellas situaciones vividas antaño que pudieron ser, bien hogareñas, bien confortables, de repente pueden tornarse en pesadillas que, una y otra vez, vienen a golpear nuestras mentes, e incluso, martirizarlas. Maurizio Cattelan, en su obra Bidibidobidiboo (1996) parece pretender acercarnos a recónditas zonas de sus más íntimos recuerdos, de sus más profundas experiencias, de sus más intensas vivencias. Muerte, angustia, desazón... son, entre otras muchas, algunas ideas que nos vienen a la mente cuando contemplamos su obra. Sea como fuere, no cabe duda de que su autor, con esta obra, consigue a la perfección que nos interroguemos sobre la misma, y que no consigamos marcar aquella delgada línea que separa lo impactante de lo siniestro.

PALABRAS CLAVE: Bidibidobidiboo, Ardilla suicida, Muerte, Lo siniestro, Unheimlich.

\begin{abstract}
Sometimes, family scenes can become into sinister scenes. Situations that could be as homey or comfortable, can suddenly turn into nightmares that, again and again, come to hit our minds, and even to martyr them. Maurizio Cattelan, in Bidibidobidiboo (1996), seems to be trying to get closer to hidden areas of his most intimate memories, or his deepest or most intense experiences. Death, anguish, uneasiness... are among many others, some ideas that come into our minds when we contemplate his work. Anyway, there is no doubt that the author, with this work, gets to perfection that we wonder about it, and it's not easy that we can mark the thin line that separates the shocking from the sinister.
\end{abstract}

KEYWORDS: Bidibidobidiboo, Suicidal squirrel, Death, The sinister, Unheimlich. 


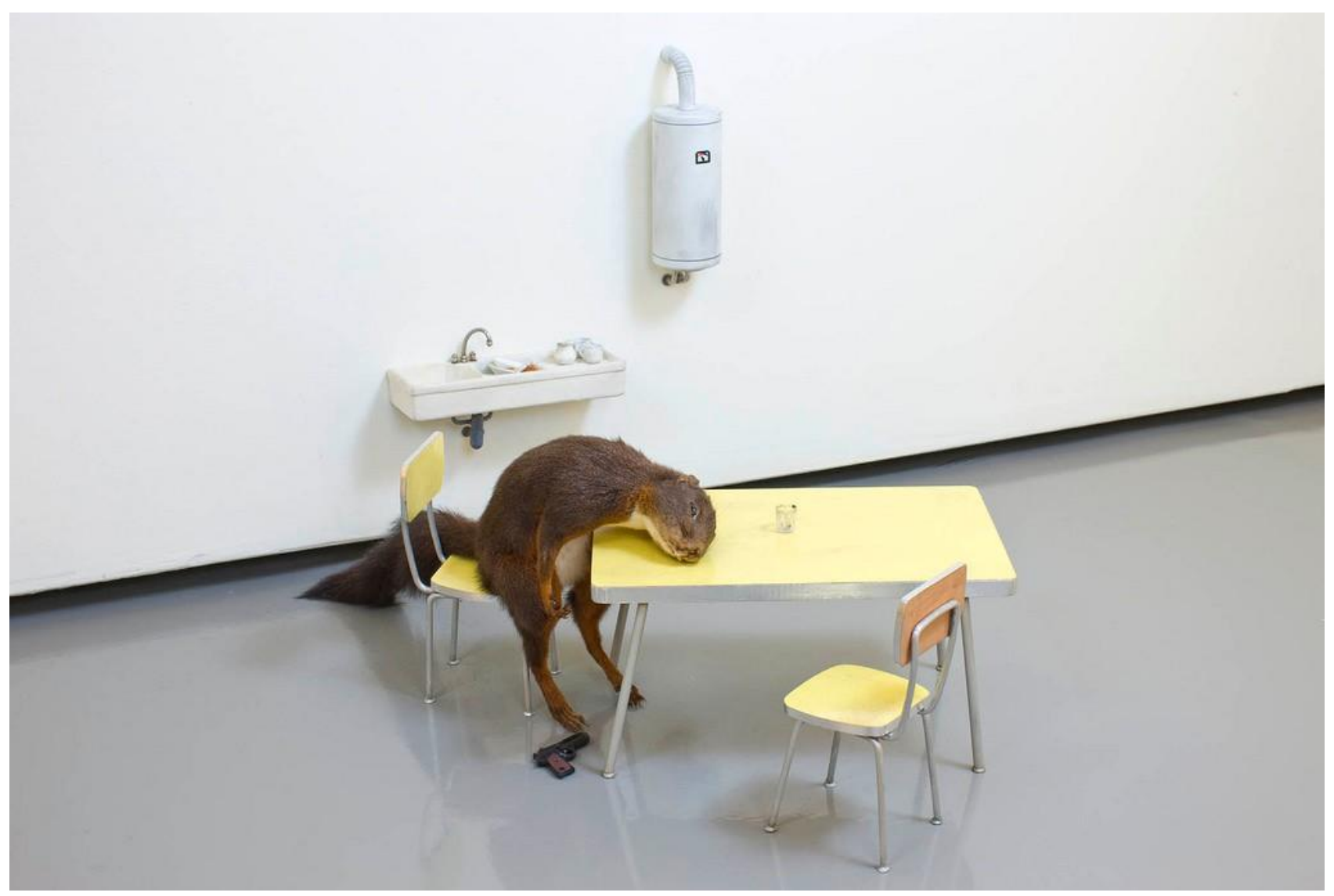

Bidibidobidiboo

Ardilla disecada, cerámica, formica, madera, pintura y acero. Dimensiones variables.

CAC Málaga, exposición temporal 03/10/2014 a 04/01/2015.

\section{Unas notas sobre lo siniestro1}

Desde las teorías estéticas kantianas, el sentimiento estético no se limita exclusivamente a lo que entendemos como bello. Pero además, Hegel aporta que la presentación de la Idea Espiritual es el mismo ámbito de la estética y así, bello y sublime, se sintetizan en una única categoría en donde la belleza es revelación de lo infinito en lo finito (Hauskeller, 2008, pp. 51-56). Lo bello inicia un camino que nos conduce a lo divino. Pero este camino se torna a veces peligroso en tanto que el rostro de la divinidad se antoja oculto, oscuro, impenetrable y así se nos invita a rebasar lo sublime para introducirnos en el ámbito de lo siniestro.

El término aparece usado en repetidas veces en Cantar de Mío Cid. Puede decirse que es la primera vez que aparece usado en castellano y, opuesto a diestro, el término siniestro alude a lo 'zurdo' o ‘torcido'. El 'mal agüero' se refiere al hado malo, a la suerte torcida, al infortunio. El 'pájaro de mal agüero' mira con envidia; esa mirada envidiosa produce infortunio y no hay mayor infortunio que recibir la mirada del adversario de Dios, "El Envidioso" (Satanás).

Freud, en Lo Siniestro (1919), utiliza el término alemán Unheimlich como "aquella suerte de sensación de espanto que se adhiere a las cosas conocidas y familiares desde tiempo atrás" (Trías,

\footnotetext{
${ }^{1}$ Para la redacción de la presente nota introductoria, se han seguido las obras de Trías y Hauskeller (cf. referencias bibliográficas)
} 
2014, p. 33). Ahora bien, ¿por qué las cosas familiares pueden tornarse siniestras? Unheimlich es antónimo de heimlich, íntimo, familiar, hogareño, doméstico... por lo que lo siniestro sería aquello que causa espanto por no resultarnos, ni familiar ni confortable. Ahora bien, no todo lo novedoso resulta espantoso, por tanto es necesario agregar algo para tornarlo siniestro. También, lo siniestro es lo que provoca desconcierto. Heimlich es lo propio del hogar, lo íntimo, aquello que nos remite al confort y seguridad del hogar. Diferenciamos a los animales mansos y domésticos de los salvajes, por tanto, heimlich es confortable, hogareño, protector, hospitalario y unheimlich por tanto es inquietante, aterra. Según Schelling, Unheimlich es "todo lo que, debiendo permanecer secreto, oculto, no obstante, se ha manifestado" (Trías, 2014, p. 34), es decir, algo familiar puede tornarse siniestro cuando pierde su halo de intimidad.

Freud asocia al término 'siniestro' a varias personas, cosas o situaciones: individuo portador de maleficios; la duda de un ser en apariencia animado cuando realmente no lo es o viceversa (figuras de cera, animales disecados, un cuadro que parece tener vida); la repetición de situaciones en idénticas condiciones a cuando se produjeron. Cuando éstas acontecen producen sensación de fatalidad; imágenes de amputaciones o lesiones de órganos especialmente delicados (ojos, genitales), despedazamientos, miembros amputados que cobran actividad; conversión de lo fantástico en real o viceversa; realización de un deseo oculto, censurado, como el deseo de mal a semejantes y que éste ocurra fatalmente... Cuando estas situaciones suceden o pueden sucederse, evidentemente, para Freud, se da lo siniestro.

Lo siniestro es, pues, lo 'fantástico encarnado'. Siguiendo a Freud, lo siniestro se da cuando ciertos complejos reprimidos se reaniman por una impresión exterior. Se repite algo familiar, pero se olvida su censura, con lo que el sujeto choca frontalmente con una realidad reprimida como la inmortalidad, resurrección de los muertos en esta vida, producción de efectos a través del pensamiento...Lo siniestro siempre se muestra oculto oscilando siempre entre realidad-ficción y ficción-realidad.

A veces reconocemos como bello el rostro en un retrato familiar porque pertenece a nuestro entorno íntimo, pero de pronto puede tornarse en siniestro en tanto que nos traiga a la mente recuerdos nefastos, quizá olvidados por represión o censura, y así revela una serie de misterios y secretos bañados en antiguos temores que hacen que una misma imagen se antoje siniestra. Lo siniestro destruye el efecto estético y así, resulta ser su límite.

Uno de los pilares que fundamentan la obra de Maurizio Cattelan (Padua, Italia, 1960) es la muerte. La taxidermia, si bien es un recurso que ha sido utilizado por muchos artistas con anterioridad, en la obra de Cattelan la técnica es recurrente con el fin de ser incluida en escenas totalmente inverosímiles, con poses ciertamente imposibles para, de algún modo, ironizar sobre la muerte, burlarse de ella. "La angustia del hombre ante los cambios vitales se entiende como una suerte de periodo que acaba, una muerte 'virtual' de una parte de nuestras vidas. Algo que nunca volverá, melancolía y tristeza representada en una ardilla suicida"2. Eso que nunca volverá, la melancolía y la

${ }^{2}$ CAC Málaga; "Presentaciones" en Maurizio Cattelan. Colección Fondazione Sandretto Re Rebaudengo. Málaga, Ayuntamiento de Málaga, 2014. 
tristeza la representa en Bidibidobidiboo: una ardilla suicida, postrada en una mesa de cocina, y con un revólver a sus pies.

El ambiente de la escena en absoluto es confortable o cálido: una cocina austera, fría, sin el calor de un hogar; la pared desnuda; la pileta de cerámica y el grifo metálico; el depósito-calentador de agua sin enmascarar su fría y funcional forma; la mesa de formica en amarillo pálido con soportes metálicos; platos y enseres sucios en la pileta que nos remiten a la posibilidad de que el personaje pretendía escapar de una realidad precaria... La ardilla toma una pose insólita, a modo de ser humano cuyo torso y cabeza se desploman sobre una mesa tras recibir el disparo de un revólver que le causa la muerte. El arma cae al gélido suelo dejando testimonio veraz del fatídico suceso. Una escena insólita y a la vez siniestra por el espanto que produce al espectador cuando la contempla.

También el título es significativo: la mágica frase del hada madrina 'Bidibi-Dobidi-Boo' ni siquiera consigue que el destino de esta humilde ardilla torne hacia una mejora social. El suicidio puede ser visto como broma cruel, de mal gusto: la ardilla estuvo viva 'sólo una vez'. Pero también la cocina, se inspira en la casa donde el artista creció, una casa un tanto ruinosa y cuya imagen se ha quedado en su recuerdo. La escena y ambientación rozan el límite de la ironía en tanto que recrea el ambiente familiar del propio artista, si bien con recuerdos nada confortables, un pasado que 'ha muerto', pero al que a la vez dispensa cierta veneración: el sujeto espectador, para contemplar la obra, debe postrarse, arrodillarse, como si rezara ante algo que pudiera ser sagrado.

\section{Una obra, ¿siniestra?}

El ambiente en donde recrea la escena, como decimos, se presenta frío, desprovisto de todo confort. No hay un mantel, una cortina, una alfombra; la mesa está desnuda y su superficie se nos antoja fría, incómoda; las paredes están igualmente desnudas, sin muebles, ni tampoco se aprecian indicios de vida familiar. Todo produce inquietud. Y en la escena, ¿hay un ser vivo o un ser muerto? ¿Se trata de un animal disecado o es un artificio?, y si está disecado ¿cómo ha muerto? Evidentemente no se ha suicidado con el revólver, es del todo imposible, pero el artista nos recrea un imposible para presentarlo como fantasía hecha realidad. Y aún surge otra pregunta: ¿desea el autor que aquel pasado humilde se autodestruya, o por contra le merece cierta veneración y por ello lo presenta de tal modo que haya que postrarse ante la obra como si de algo divino se tratase? Aquí radica lo siniestro.

Se trata de algo indeterminado, realmente desconocido, inquietante, espantoso. Nos espanta ver un animal muerto, aunque parece estar vivo por el realismo de la técnica taxidermista. No se puede tocar por estar dentro de una urna, por tanto, ¿se trata de algo sagrado o más bien profano?, ¿debemos rendirle culto o bien debemos mostrar animadversión o repulsa?, ¿es realidad o ficción?, el escenario, ¿es real o pertenece al ámbito de la imaginación?, la acción, ¿es realmente fruto de un desenlace fatal o por el contrario es deseada en lo más íntimo del autor y, fatalmente ha acaecido?

Es en la ambigüedad e indefinición de estas preguntas sin respuesta donde aparece lo siniestro. Hay algo inquietante, poco familiar; algo a lo que no estamos acostumbrados, nos incomoda, mostramos cierta repulsa, pero a la vez despierta una curiosidad morbosa. Se trata de un ser que, otrora fuese animado, ora no lo es, pero en cualquier instante podría volver a la vida porque no se ha 
deteriorado, es eterno, sus atributos naturales se nos presentan cual si dormido estuviese. Pero la pose es totalmente insólita ya que una ardilla jamás dormiría sentada en una silla y recostaría su cabeza sobre una mesa. Desearíamos que nunca hubiese acaecido tan fatal desenlace, pero es que la historia nunca ocurrió: la ardilla jamás entró en la cocina, ni se sentó a la mesa, ni tomó el revólver y, ni mucho menos, se suicidó. Nada de esto ocurrió, todo es fantasía, pero Cattelan nos lo muestra tal cual si hubiese ocurrido. ¿Se trata entonces de la repetición -o recreación- de una situación o acontecimiento en condiciones idénticas a como aconteció realmente? Aquí también radicaría la categoría de lo siniestro: cuando una situación se repite en idénticas condiciones a como sucedió, la sensación que provoca es un tanto siniestra en tanto que nos incomoda, nos aturde, nos hace pensar que hay un doble que vive nuestras mismas situaciones. ¿Es ésta entonces la intención del autor?, ¿pretende realmente hacernos sentir incómodos haciéndonos partícipes de una acción que él mismo pudo remotamente contemplar?, ¿sucedió algo similar en el pasado? He aquí lo inquietante y oscuro de la escena; elementos todos que la convierten en siniestra.

\section{Conclusión}

¿Dónde radica entonces el deseo del sujeto-espectador? ¿Desea que el animal vuelva a la vida o por el contrario desea que no resucite? ¿Qué sería más inquietante? ¿Qué resulta más aterrador y espantoso: contemplar al animal muerto por un disparo que nunca se ha realizado o bien que de pronto volviese a la vida?, y por su lado ¿desea el autor rememorar un pasado difícil y extremadamente adverso o bien plasma un deseo oculto de mal hacia su prójimo de tal modo que fatalmente se está llevando a cabo?

Cuestiones inquietantes y a la vez asombrosas; escena intrigante pero que podría despertar ternura, también repulsión, pero no podemos dejarla de lado. Ahí radica lo siniestro: es familiar, sabemos qué ha ocurrido, pero no el porqué; es inquietante, reside en la fantasía porque la escena se ha podido recrear en la imaginación o recuerdo de su autor. Obra siniestra por mostrar ese lado oscuro, escondido, íntimo, profundo. Siniestra por mostrar aquella zona recóndita en donde la mente elabora deseos censurados pero que subyacen plasmados en las artes y liberan a sus autores de su quizá secreta culpabilidad.

\section{Referencias bibliográficas}

CAC Málaga (2014), Maurizio Cattelan. Colección Fondazione Sandretto Re Rebaudengo. Ayuntamiento de Málaga, Málaga.

CAC Málaga, http://cacmalaga.eu/2014/10/03/maurizio-cattelan-4/ (Consultado: 8/02/2015).

HAUSKELLER, Michael (2008), ¿Qué es el arte? Posiciones de la estética desde Platón a Danto. Editilde, Valencia.

TRÍAS, Eugenio (2014), Lo bello y lo siniestro. Debolsillo, Barcelona.

Maurizio Cattelan: The Site, http://mauriziocattelan.altervista.org/ (Consultado 8/02/2015). 